\title{
Contextualising Information Quality: A Method-Based Approach
}

\author{
Markus Helfert ${ }^{1}$ and Owen Foley ${ }^{2}$ \\ ${ }^{1}$ School of Computing, Dublin City University, Glasnevin, Dublin 9, Ireland \\ ${ }^{2}$ School of Business, Galway Mayo Institute of Technology, Dublin Road, Galway, Ireland \\ markus.helfert@computing.dcu.ie, owen.foley@gmit.ie
}

\begin{abstract}
Information Quality is an ever increasing problem. Despite the advancements in technology and information quality investment the problem continues to grow. The context of the deployment of an information system in a complex environment and its associated information quality problems has yet to be fully examined by researchers. Our research endeavours to address this shortfall by specifying a method for context related information quality. A method engineering approach is employed to specify such a method for context related information quality dimension selection. Furthermore, the research presented in this paper examined different information systems' context factors and their effect upon information quality dimensions both objectively and subjectively. Our contribution is a novel information quality method that is context related; that is it takes the user, task and environment into account Results of an experiment indicate as well as feedback from practitioners confirm the application of our method and indeed that context affects the perception of information quality.
\end{abstract}

Keywords. Information quality, Method, Context, Method engineering.

\section{Introduction}

With the increasing importance of Data and Information Quality (DIQ), much research in recent years has been focused on developing DIQ frameworks and dimensions as well as assessment approaches. Researchers have developed a plethora of frameworks, criteria lists and approaches for assessing and measuring DIQ. Despite the vast amount of DIQ research, discussions with experts and practitioners as well as recent studies indicate that assessing and managing DIQ in organizations is still challenging and current frameworks offer only limited benefit.

Several researchers have addressed the question on how to define DIQ and many have confirmed that DIQ is a multi-dimensional concept $[1,2]$. Following prominent definitions of "quality" as "fitness for use", most researchers acknowledge the subjective nature of data and information quality. Aiming to assess DIQ, many objective and subjective assessment techniques have been proposed. Mostly, these are developed for one specific context or domain, with limited general applicability. Furthermore, despite the inherent subjective character of quality, foremost frameworks and assessment methodologies are limited to consider the subjective character in which the assessment is performed. 
Objective DIQ assessment uses software to automatically measure the data in database by a set of quality rules whereas subjective DIQ assessment uses a survey or interview approach to measure the contextual information by data consumers. A single assessment result can be obtained from objective DIQ assessment. However, we may obtain different assessment results from different information consumers. With the development of both objective and subjective DIQ assessment, researchers suggested to combine these two assessment methodologies. For example, Pipino et al. [3] provide a framework to combine objective and subjective DIQ assessments. Kahn et al [4] propose the PSP/IQ model, in which they assign two views of quality: conforming to specifications (objective) and meeting or exceeding consumer expectations (subjective).

Recognising the problem of limited context in DIQ frameworks, the aim of this paper is to present an approach, which assist in adapting DIQ frameworks to various contexts. In our work we follow the recent observation by researchers, to adapt research results to specific application by providing an approach of contextualising models [5]. In contrast to contribute yet another DIQ framework, in this article, we describe a method to contextualise DIQ frameworks. In this sense, "context" relates the content of the DIQ framework to the IS environments [6]. Context itself is described by various contextual factors characterizing the IS environment. Following design science research, the method is being developed and refined using a method engineering (ME) approach. The proposed method was developed based on experiences from the airline industry. A number of experiments are conducted to test the proposed method. In addition, IS professionals are interviewed to further verify the method and to study the impact of IS context on DIQ.

The paper is organised as follows. The research is introduced in general terms followed by an outline of the problem statement and objective. A review of related IQ work as a field within IS follows. Subsequently, details of the contextualisation method together with an initial application are presented. Contribution, limitations and future work conclude the paper.

\section{Problem Statement and Research Objective}

As a direct result of user dissatisfaction with the quality of the information produced by IS [7], practitioners and researchers have been concerned for several years about the quality of information and data. The problem becomes increasingly important with the rapid growth in the amount of data that enterprises store and access [8-10]. The information -often of poor IQ- is being used ever increasingly for critical decision making at all levels within the organisation, resulting in significant IQ related problems.

Some examples of these problems are summarized for instance in Al Hakim [11] who provides examples from many areas, outlining the reason along with the particular IQ dimension affected. The examples indicate how the generation of information from disparate sources can impact on many aspects of an enterprise, often not even considered when the IS was initially designed. The impact of these IQ problems has prompted researchers to examine such aspects as IQ dimensions, IQ assessment and IQ management. The impact of the various dimensions of IQ requires 
measurement and examination. Furthermore, there has been a huge financial impact associated with the lack of IQ. For instance, it is estimated that poor quality information costs American business some $\$ 611$ billon a year [12]. Addressing this problem, several enterprises have invested considerably in efforts to "clean up" their information, to improve IQ and to define rules and routines to assess and manage IQ.

Research has addressed this challenge from various directions. Management process and guidelines have been proposed in order to manage IQ. The database community has contributed several approaches for data cleansing and assessing data quality in databases. In addition, software engineering has focused on improving the quality of software. As a result, research related to IQ has evolved significantly over the last two decades. Numerous frameworks, dimensions and metrics have been put forward [1, 2]. Approaches have been developed to measure the impact of these dimensions on IQ and to improve IQ. However, the benefits of these approaches such as better quality software, easier to use systems, readily acceptable software and increased IQ all have the potential to be foregone by changing contexts or situations.

The evolving nature of IS context presents new and very distinct challenges to IQ research. Primarily among these is the dynamic nature of IS context. IS designers no longer have the luxury of complete control over the nature of the IS context post deployment of the IS. Usually software systems are developed with tried and tested methodologies for a particular context with certain requirements. IQ measurements and management approaches can be defined and deployed for this particular context. Once implemented, contexts evolve and requirements may change. However with such fundamental changes in context, a question about its impact on IS become significant $[13,14]$.

IQ measurements and management approaches are usually not evolving along the various contexts, and indeed changes in context do usually not undergo a systematic consideration. Systems and IQ measurement approaches are developed for a particular context. Nonetheless the importance of a high level of IQ remains a requirement. As a result often the perception of IQ via subjective survey instruments is progressively getting poorer [15]. Indeed, this observation may explain a frequent criticism, that despite large investments in IQ and software systems, end users are still not satisfied with IQ and the usability of systems. Variation in the context, require adaptation of the IQ measurement approach to cater at least for different requirements and changes in perception. Presently the approach to a changing context and IQ is ad-hoc and not systematic.

The problem can be illustrated by an example from the airline sector, which has been examined by us. The organisation has an airline maintenance and information system in use for many years. Different types of users using the IS on a regular basis for the performance of their duties. Also, for several years the organisation has IQ routines and assessment approaches in place. Pilots, engineers, administrators and technicians are required to rate the IQ of the system on a regular basis for quality control and legal obligations. Surprisingly, over the last two years, the MIS (Management Information Systems) department has experienced a dramatic increase for requests to verify IQ of the IS. This has become a very resource intensive exercise with many of the requests requiring no alteration to data values. On closer examination, we observed that in tandem with the increase in IQ requests the IS context has changed. For instance, the access modes to the system have changed over the years. The single point of access via data entry personnel has evolved over time to 
the point where many users interface with the IS from mobile devices over wireless networks. As a consequence, the procedures and IQ assessment approaches in place did not reflect the current situation with various access modes and changing contexts. The organisation did not have any systematic approach to cater for these changes.

The brief example from the airline industry illustrates the requirement for a systematic approach to adapt IQ frameworks for various contexts. Our approach presented in this article, assists to contextualise IQ frameworks and thus cater for various and changing contexts. The necessity for this research arises from the ever increasing dynamics that exists with respect to IS deployment. As our observation from the case study shows, perceptions of IQ may alter as the result of evolving contexts. Research related to IQ has not or only in a limited manner addressed and recognised this problem. In contrast to define yet another IQ framework, we believe that the application of existing IQ frameworks requires a clear, concise and systematic approach to cater for dynamic and evolving contexts. The traditional static deployment of IQ frameworks do not consider adequately the changing factors of IS context. The challenge of this research is to specify a systematic approach in the form of a method that considers the IS context, allowing for the evaluation of IQ in various contexts.

\section{Related Work}

Our work builds on and contributes to the research related to IQ, which has developed a large number of frameworks, assessment approaches and criteria list. An overview of research related to IQ is provided for instance in Ge and Helfert [16]. Ge and Helfert have examined the definition of IQ and suggest that it can be defined from a consumer perspective and a data perspective. The concept of fitness for use [2] is widely regarded in the literature as a definition for IQ from the consumers view point.

Table 1. Selected Information quality frameworks and its application context.

\begin{tabular}{|l|l|l|l|}
\hline $\begin{array}{l}\text { Author and year of } \\
\text { Publication }\end{array}$ & Application context & $\begin{array}{l}\text { Author and year of } \\
\text { Publication }\end{array}$ & Application context \\
\hline Morris et al. 1996 [17] & Management & Huang et al. 1999 [18] & Knowledge Management \\
\hline Redmann 1996 [7] & Data Bases & $\begin{array}{l}\text { Chengalur-Smith et al. } \\
\text { 1999 [19] }\end{array}$ & Decision-Making \\
\hline Miller 1996 [20] & Information Systems & Berndt et al. 2001 [21] & Healthcare \\
\hline Wang/Strong 1996 [2] & Data Bases & Xu et al. 2002 [22] & $\begin{array}{l}\text { Enterprise Resource } \\
\text { Planning }\end{array}$ \\
\hline Davenport 1997 [23] & $\begin{array}{l}\text { Information } \\
\text { Management }\end{array}$ & Helfert/Heinrich 2003 [24] & $\begin{array}{l}\text { Customer Relationship } \\
\text { Management }\end{array}$ \\
\hline Ballou et al.1998 [25] & Data Warehousing & Amicis/ Batini 2004 [26] & Finance \\
\hline Kahn/Strong 1998 [27] & Information Systems & Xu/Koronios 2004 [28] & E-business \\
\hline Rittberger 1999 [29] & $\begin{array}{l}\text { Information Service } \\
\text { Providers }\end{array}$ & Knight/Burn 2005 [15] & World Wide Web \\
\hline English 1999 [30] & Data Warehousing & Li/Lin 2006 [31] & $\begin{array}{l}\text { Supply Chain } \\
\text { Management }\end{array}$ \\
\hline Ballou/Tayi 1999 [32] & Data Warehousing & & \\
\hline
\end{tabular}


The definition of IQ from a data perspective examines if the information meets the specifications or requirements as laid down in IS design. IQ from a consumer perspective led to the development of subjective IQ measures, whereas IQ from a database perspective resulted in objective IQ measures.

Many IQ frameworks have been developed in order to classify dimensions that will allow for IQ assessment. As shown in table 1, we reviewed prominent frameworks and analyzed these according to the application context for which they were proposed. Although claims are sometimes made to provide a generic criteria lists, on closer examination most research has been focused on investigating IQ within a specific context. The frameworks differ in selected IQ criteria as well as assessment techniques.

The complexity of the information system architecture is just one of several contextual factors to characterise IS environments. In literature there is strong support that types of users and types of IS result in different requirements and therefore perceptions of DIQ [33-35]. Empirical research concluded that user evaluation of IS is directly influenced by system, task and individual characteristics. Besides, several examples in DIQ literature illustrate that the departmental (organisational) role plays an important factor in user's opinion and perspectives [11, 33, 36]. Although recognising that there are several contextual factors, in our research we limit the set of contextual factors to 4 :

(1) User role

(2) Organisational department,

(3) IS Architecture

(4) Task complexity.

The initial deployment of an IS generally caters adequately for these context factors. However over time these evolve and require a fresh analysis in order to accurately represent the true nature of the context of the IS. This can only be done if examinations of the factors within a context are continually updated and revised. These factors can be further classified with appropriate components. The updating of the factors and reclassification of components should be carried out in an iterative and systematic fashion similar to TDQM [37].

Table 2. Common IS Context Factors.

\begin{tabular}{|l|l|}
\hline Factor & Component \\
\hline User Role & Manager / Specialist \\
\hline Organisational Department & IT Department / Non IT Department \\
\hline IS Architecture & Workstation, Service Oriented, Mobile \\
\hline Task Complexity & Operational, Strategic \\
\hline
\end{tabular}

The significant change and increase in complexity of IS context has in many cases occurred independently of the underlying databases that are accessed [13]. An application may have been designed, built and tested with a mature software development method for a particular context. Yet within a very short period of time it may be accessed and predominantly employed from a different context [11]. Data models have also evolved [9]. However a considerable number of IS in use today have data models designed prior to the contexts that are employed to access them. There are as a result multiple accesses from diverse and complex contexts. 


\section{A Method for Contextualising IQ Frameworks}

In order to develop an approach to contextualise IQ frameworks, we follow design science and apply a method engineering (ME) approach. ME as a discipline has been recognised over the last decade. It is concerned with the process of designing, constructing and adapting generic artefacts such as models, methods, techniques and tools aimed at the development of IS [38]. Punter [39] describes the discipline from a process perspective where methods are comprised of phases, phases are comprised of design steps, and design steps are comprised of design sub-steps. He states that to every design step or sub-step, certain product-oriented method constituents (e.g. techniques, procedures) can be assigned.

In order to describe methods, Gutzwiller [40] proposes a meta-model for methods that includes activities, roles, specifications, documents and techniques. Figure 1 below illustrates the relationship between these elements. The meta-model facilitates a consistent and concise method, which in turn allows for their application in a goal oriented, systematic and repeatable fashion. According to Gutzwiller [40] activities are the construction of tasks which create certain results. These activities are assigned to roles and the results are recorded in previously defined and structured specification documents. The techniques comprise of the detailed instructions for the production of the specification documents. Tools can be associated with this process. The metamodel describes the information model of the results.

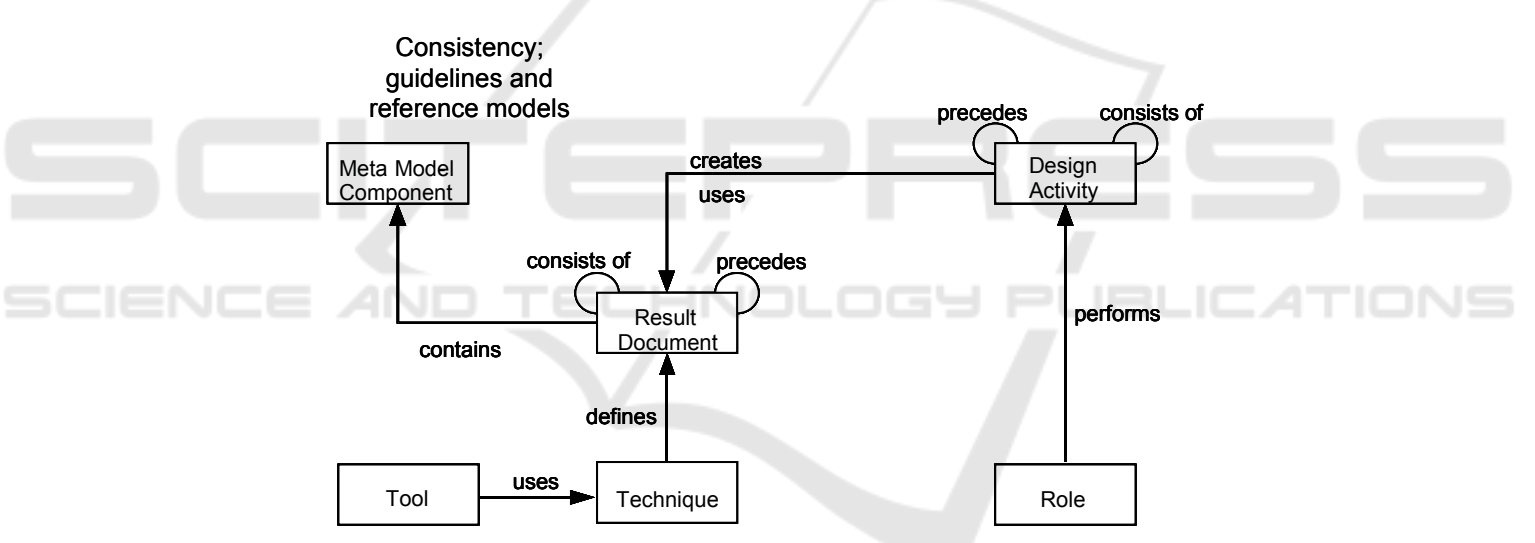

Fig. 1. Method Engineering Approach.

Applying a method based perspective on contextualising IQ frameworks, we identified four main activities that describe the contextualisation process: (1) Identify and prioritising contextual factors, (2) Selecting and prioritise IQ dimensions with associated IQ measures, (3) Implement IQ measures, (4) review and improve.

Besides the contextualisation process (activities), the second main element is the description of result documents. We provide a consistent result document for contextualised IQ frameworks. The meta-model is illustrated in Figure 2 that outlines the relationship between the different components of context factors and IQ measurements. 


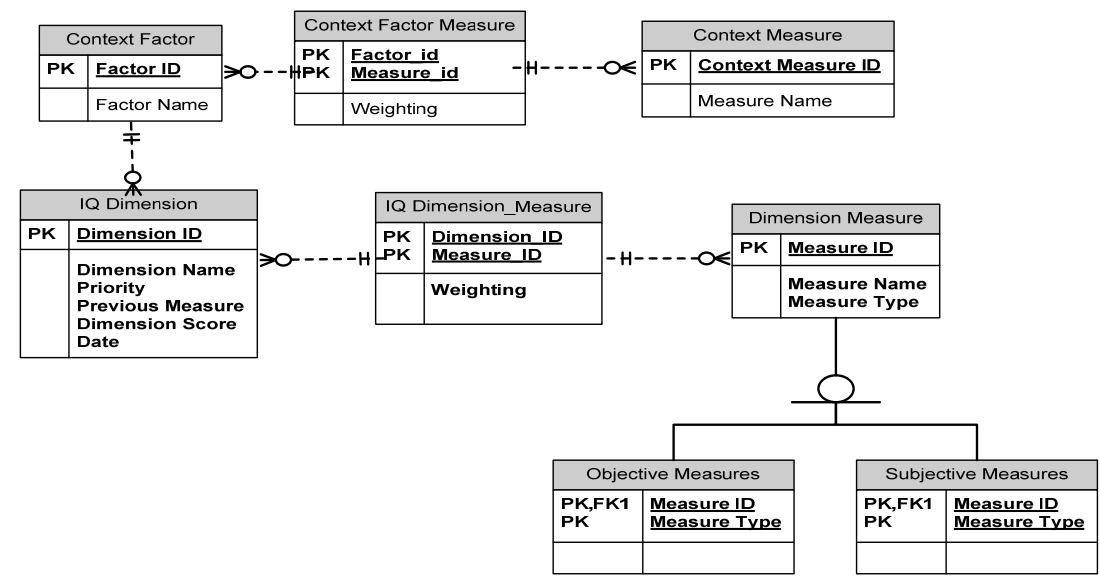

Fig. 2. Meta Model for Contextualising IQ Frameworks.

The initial application of the ME approach to our problem was examined with respect to a library IS. A diverse user population accesses this IS from three different contexts. Figure 3 specifies the general contextualisation processes that allow us to conduct an experiment to validate our approach. We consider 4 main activities (1) Identify contextual factors, (2) Quantify and prioritise IQ requirements, (3) Implement selected IQ Measures, (4) Improve. Activity (1) is usually carried out by the IS Manager, involving interviews and surveys with domain experts. This activity completes and measures context factors. Activity (2) identifies and prioritises IQ metrics and requirements. Carried out by Business Analysts, for this activity and to priorities IQ dimensions we selected a specific technique: Leung's metric ranking. Subsequently the Information Technology Manager and Software developers implement the IQ measures, in the form of Service Analysers, Integrity Checker and IQ surveys. Finally, IS manager, Information Technology managers together with the Business Analyst review the context factors as well as IQ measures, and thus initiate a continuous improvement process.

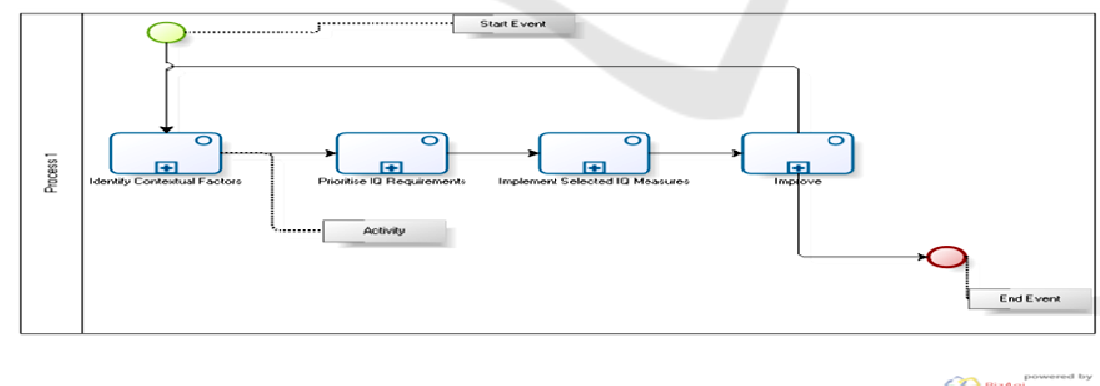

Fig. 3. High Level View of IQ Dimension Selection Method.

This general contextualisation process was detailed in sub-processes. Figures 4 to 7 outline in detail the process description that is required in order to apply our method. In conjunction with the meta-model in figure 2 , the result of the subsequent 
processes, provides us with a detailed set of activities and tools that allow for context factor and dimension selection.

In order to select appropriate context factors as described in figure 4 the role groups of the IS, tasks, associated IS service and access devices are identified and assessed. This assessment is done in conjunction with the domain users and IS experts. Upon identification of these a classification order is assigned to each of the context factors. The context factor and context factor measure tables in figure 2 are propagated with the appropriate values.

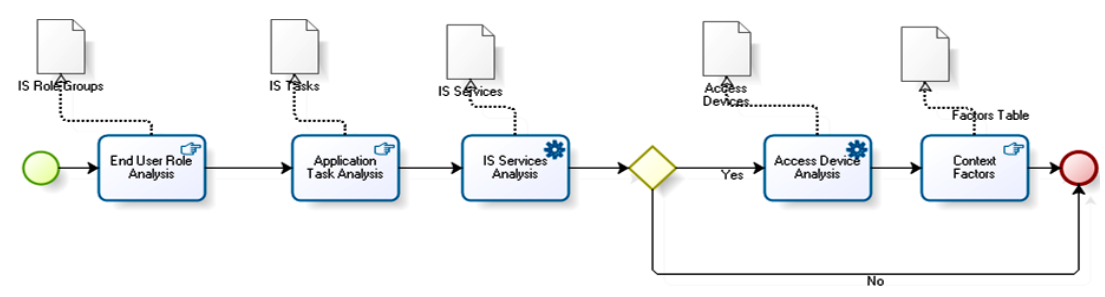

Fig. 4. Identify Contextual Factors.

Upon identification of the context factors there is a requirement to identify and prioritise dimension selection appropriate to a particular context. This requires domain experts, IS and IT managers to rank dimensions in order of priority. This may involve the application of domain metrics or survey instruments to ascertain the most important dimensions. Once this process is completed the appropriate dimension tables outlined in figure 2 are updated.

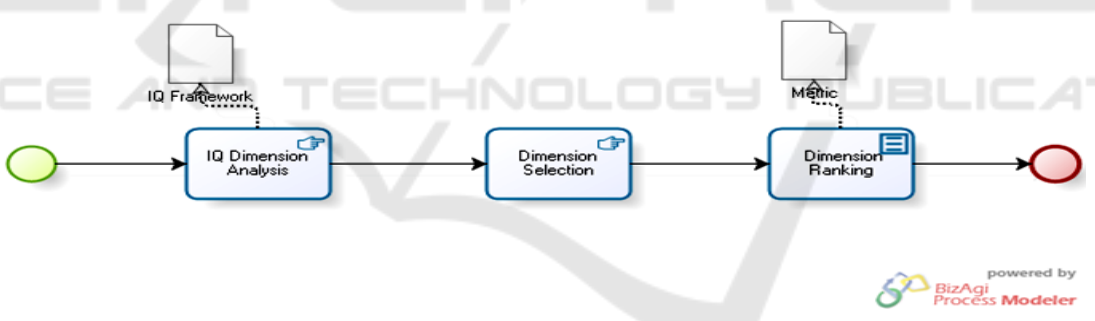

Fig. 5. Prioritise IQ Dimension Requirement.

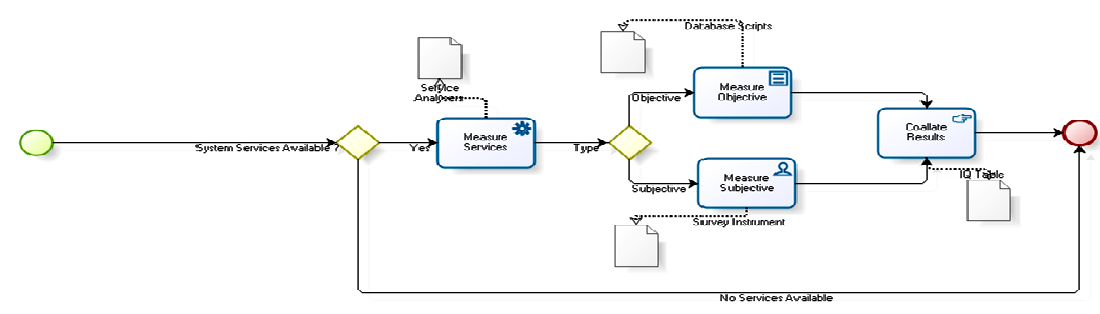

Fig. 6. IQ Measurement. 
The selection of appropriate dimensions requires them to be measured. It is important that the sequence of measures is followed correctly as outlined in figure 6 . The measures as outlined in table 3 require the availability of services to be checked initially followed by the objective database and subjective measures.

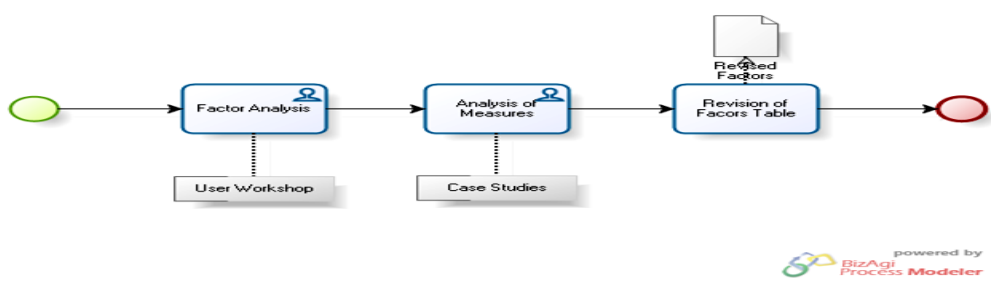

Fig. 7. Improve.

The final process of improvement involves revised context factor analysis by means of user work and measures. The revised factors are updated in the contect factors table.

The contextualisation process and the result meta-model are further extended by a set of objective and subjective IQ measures. These are part of the meta-model in Figure 2. The objective measures are further subdivided into two categories data base integrity measure and software service measure. A summary of the objective and subjective IQ measures is available in Table 3. Subjective IQ Measures follow a common questionnaire approach, using questionnaire construct and a 5-point Likert scale.

Now we have described the process steps (activities) for contextualising IQ frameworks. Further we have specified objective and subjective measures for IQ. Reviewing the meta model in Figure 2, we also need to specify how various IQ measures from different IQ dimensions are aggregated.

Many researchers have proposed ways to aggregate single measures of IQ dimensions, often underlying a weighted aggregate of single values for IQ dimensions [2]. Although, recently some researchers have attempted to propose IQ value curves and trade-offs by analysing the potential impacts of IQ, many researchers propose to measure the overall impact of IQ as weighted aggregate. A principle measure of the weighed sum of all the criteria $\left(\mathrm{IQC}_{\mathrm{i}}\right)$ is illustrated below

$$
I Q=\sum_{i=1}^{N} \alpha_{i} I Q C_{i} \quad \text { where } \begin{aligned}
& \forall \alpha_{i}: 0 \leq \alpha_{i} \leq 1 \\
& \sum_{i=1}^{N} \alpha_{i}=1
\end{aligned}
$$

Equation 1. Aggregate measure of information quality.

We follow this prominent aggregation of IQ measures by weighted sums. This is reflected in our method and meta-model by specifying priorities in forms of weights. The aggregated value should define the quality level that characterizes information source. The approach to use the average as an aggregation functions may not be suitable among heterogeneous dimensions since dependencies introduces bias that negatively affect the reliability of the assessment procedure. This might be problematic, as changes in the context will have an impact on other dimensions and as a consequence the aggregate score. 
Table 3. Information Quality Measures.

\begin{tabular}{|c|c|c|c|}
\hline & Measure Name & Description & Measure \\
\hline \multirow{4}{*}{ 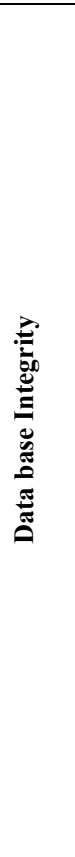 } & Free-of-Error & $\begin{array}{l}\text { The dimension that represents } \\
\text { whether data are correct. }\end{array}$ & $\begin{array}{l}\text { Free-of-Error Rating }=1-\left\langle\frac{N}{T}\right\rangle \\
\text { Where } N=\text { Number of data units } \\
\text { in error and } T=\text { Total number of } \\
\text { data units. }\end{array}$ \\
\hline & Completeness & $\begin{array}{l}\text { Schema, Column and } \\
\text { Population }\end{array}$ & $\begin{array}{l}\text { Completeness Rating }=1-\left\langle\frac{C}{T}\right\rangle \\
\text { Where } C=\text { Number of } \\
\text { incomplete items and } T=\text { Total } \\
\text { number of items. }\end{array}$ \\
\hline & Consistency & Referential Integrity, Format & $\begin{array}{l}\text { Consistency Rating }=1-\left\langle\frac{C}{T}\right\rangle \\
\text { Where } C=\text { Number of instances } \\
\text { violating specific consistency } \\
\text { type and } T=\text { Total number of } \\
\text { consistency checks performed. }\end{array}$ \\
\hline & Timeliness & $\begin{array}{l}\text { The delay in change of real } \\
\text { world state compared to the } \\
\text { modification of the ISs state. } \\
\text { The difference between the } \\
\text { times when the process is } \\
\text { supposed to have created a } \\
\text { value and when it actually has. }\end{array}$ & $\begin{array}{l}\text { Timeliness Rating }=\mathrm{R}-\mathrm{I} \\
\text { Where } R=\text { IS State Time } I= \\
\text { Real World Time }\end{array}$ \\
\hline \multirow{3}{*}{ 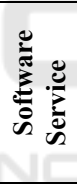 } & Database Listener & \multicolumn{2}{|c|}{\begin{tabular}{l|l} 
DB process & Binary Measure \\
\end{tabular}} \\
\hline & Web Service & \multicolumn{2}{|l|}{ Web Service Process } \\
\hline & Mobile Access & Security Access & \begin{tabular}{l|l} 
User Profile Dependent \\
\end{tabular} \\
\hline \multirow{4}{*}{ 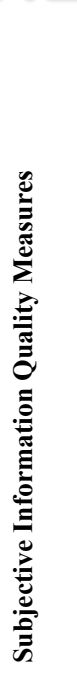 } & Timeliness & \multicolumn{2}{|c|}{$\begin{array}{l}\text { This information is sufficiently current for our work. } \\
\text { This information is not sufficiently current for our work. } \\
\text { This information is sufficiently timely. } \\
\text { This information is sufficiently up-to-date for our work. }\end{array}$} \\
\hline & Free of Error & \multicolumn{2}{|c|}{$\begin{array}{l}\text { This information is correct. } \\
\text { This information is incorrect. } \\
\text { This information is accurate. } \\
\text { This information is reliable. }\end{array}$} \\
\hline & Completeness & \multicolumn{2}{|c|}{$\begin{array}{l}\text { This information includes all necessary values. } \\
\text { This information is complete. } \\
\text { This information is sufficiently complete for our needs. } \\
\text { This information covers the needs of our tasks. } \\
\text { This information has sufficient breadth depth for our task. }\end{array}$} \\
\hline & Consistency & \multicolumn{2}{|c|}{$\begin{array}{l}\text { This information is consistently presented in same format } \\
\text { This information is presented consistently. } \\
\text { This information is represented in a consistent format. }\end{array}$} \\
\hline
\end{tabular}




\section{Initial Application and Analysis}

We applied the developed Method to contextualise IQ Frameworks in an experiment involving 48 users. By considering various contexts, this allows us to measure the impact of the context on the perception of IQ. The USER ANALYSIS in Figure 4 identified 3 groups broken down between librarians, library users and technicians. This involved the users completing a number of TASKS with respect to information retrieval as they pertained to each particular group. The selected dimensions of the framework for the particular ENVIRONMENT are then broken down into objective and subjective measures. The results from application of the measures are compared upon completion.

The tasks for each user group were specific to that group. Members of the groups were randomly allocated to each of the access devices. The experiment involved control of one independent variable namely the access device. Each of the groups were assigned tasks particular to their profile. The tasks within each group were conducted from three different contexts namely workstation, web, and mobile. The first requirement of the method is to analyse the software services identified and selected. This is a binary test and examines the availability of the service. The application of the method first checks the availability of the three software services identified. In the event of service availability the objective integrity analysers are initiated. The results of this analysis are stored in an IQ table-space similar to an audit table-space [41]. The subjective survey instrument is run in conjunction with the objective integrity analysers.

The analysis of results indicate that a relationship exists between the level of IQ and the context of IS access. This confirms the requirement to select IQ dimensions appropriate to individual contexts. The implementation of our method and its validation by means of an experiment demonstrate the significance of context. A uniform application of dimensions without consideration for context we contend will not accurately reflect the true state of IQ for an IS.

We describe the process of data collection and analysis. The initial step in the analysis is the binary test of services. This important step in our method as outlined in Figure 6 it allows for the identification of dimensions associated with various software services. Subjective analysis only takes place when this analysis is complete. All the services were present therefore the subjective and objective tests were applied to all participants. In order to test the level of significance of the remainder of the results it is necessary to apply an appropriate statistical technique to the data gathered. We need to ascertain if there is a relationship between the context of the IS (Web, Workstation or Mobile) and the level of IQ. As IQ is a multidimensional concept it is necessary to do this at a dimension level.

There is a clear indication from this initial analysis that the context of the IS is significant. However in order to strengthen and build on this finding Field [42], suggests that appropriate inferential statistical techniques should be applied. A review of this literature indicates that One Way Independent Analysis of Variance (ANOVA) is appropriate. Field [42] also suggests that this technique be used when three or more statistical groups and different participants in each group will be used. 
Based on confidence interval of $95 \%, \mathrm{v}_{1}=2$ and $\mathrm{v}_{2}=27$, the critical $\mathrm{F}$ statistic, $\mathrm{F}_{.05,2,15}=3.354$ are within the "Reject $\mathrm{H}_{0}$ " which leads us to the conclusion that the population means are not equal.

The ANOVA test statistically indicates that the population means are not even. We have rejected $\mathrm{H}_{0}$. Caulcutt [43] indicates that it is possible to determine which of the sample means is statistically significant using the Scheffé Test. According to our results statistically users rate the IQ dimension of free-of-error best from the workstation context in comparison with both web and mobile. They also rate the web context statically more significant or satisfied than the mobile context.

\section{Summary, Future Research and Limitations}

This research contributes to the analysis of IS context and IQ. Although frequently mentioned, foremost research lacks in explaining adequately the impact that IS context has on IQ [15]. In recent times companies have invested heavily in IQ programmes in an effort to improve IQ [11]. Our research demonstrates that a relationship exists between IS context and other dimensions in an IQ framework. We have specified a method that allows context to be considered when selecting dimension. The traditional techniques of measuring IQ dimensions will also require examination as relationships between the context and other dimensions have also been established. This research contributes to the field of IQ research by providing a method and test environment that can be employed in a context related manner. It has the potential to allow organisations to measure the impact of introducing new contexts post the development of an IS.

Although the research revealed interesting results, our research currently concentrates only on a subset of dimensions. The application of further experiments addresses this limitation. Correlation has been used to examine the relationship between IQ dimensions; Analysis of Variance will be completed for all sections of the research. This will allow for a full examination of experimental data. Furthermore it is intended to improve and extend the prototypical implementation of the tool as software application.

\section{References}

1. Wand, Y. and R. Wang, Data Quality Dimensions in Ontological Foundations. Communications of the ACM, 1996. 39: p. 184-192.

2. Wang, R. and D. Strong, Beyond Accuracy: What Data Quality Means to Data Consumers. Journal of Management Information Systems, 1996. 12: p. 5-34.

3. Pipino, L., Y. Lee, and R. Wang, Data Quality Assessment. Communications of the ACM, 2002: p. 211-218.

4. Kahn, B. and D. Strong, Information Quality Benchmarks: Product and Service. Communications of the ACM, 2002: p. 184-192.

5. Recker, J., et al. Model-Driven Enterprise Systems Configuration. in 18th Conference on Advanced Information Systems Engineering. 2006. Luxembourg: Springer.

6. Lee, Y., Crafting Rules: Context-Reflective Data Quality Problem Solving. Journal of 
Management Information Systems, 2004. 20(3): p. 93-119.

7. Redman, T., Data Quality for the Information Age. 1996: Artech House Publishers.

8. AlHakim, L., Challenges of Managing Information Quality in Service Organizations. 2007: Idea Group Pub.

9. Date, C., Databases in Depth. 2005: O Reilly.

10. Loshin, D., Enterprise Knowledge Management - The Data Quality Approach. 2001: Morgan Kaufmann.

11. AlHakim, L., Information Quality Management Theory and Applications 2007.

12. Olson, J., Data Quality: The Accuracy Dimension. 2003: Morgan Kaufmann.

13. Adelman, S., L. Moss, and M. Abai, Data Strategy. 2005: Addison-Wesley.

14. Sangwan, R., et al., Global Software Development Handbook. 2007: Auerbach Publications.

15. Knight, S. and J. Burn, Developing a Framework for Assessing Information Quality on the World Wide Web. Informing Science, 2005. 8: p. 159-172.

16. Helfert, M. and M. Ge. A Review of Information Quality Research. in 11th International Conference on Information Quality. 2006.

17. Morris, S., J. Meed, and N. Svensen, The Intelligent Manager. 1996, London: Pitman Publishing.

18. Huang, K., Y. Lee, and R. Wang, Quality Information and Knowledge Management. 1999.

19. Chengalur-Smith, I. and P. Duchessi, The Initiation and Adoption of Client Server Technology in Organizations. Information and Management, 1999. 35(7): p. 77-88.

20. Miller, An expanded instrument for evaluating information system success. Information and Management, 1996. 31(2): p. 103-118.

21. Berndt, E.R. and D.M. Cutler, Medical Care Output and Productivity. 2001: National Bureau of Economic Research.

22. Xu, H., et al., Data Quality Issues in implementing an ERP. Industrial Management \& Data Systems, 2002. 102(1): p. 47-59.

23. Davenport, T., Information Ecology: Mastering the Information and Knowledge Environment. 1997, Oxford: Oxford Universirty Press.

24. Heinrich, B. and M. Helfert. Analyzing Data Quality Investments in CRM: a Model Based Approach. in 8th International Conference on Information Quality. 2003. Boston, Massachusetts, USA.

25. Ballou, D.P., et al., Modelling Information Manufacturing Systems to Determine Information Product Quality. Management Science, 1998. 44(4): p. 462-484.

26. Amicis, F.D. and C. Batini, A Methodology for Data Quality Assessment on Financial Data. Studies in Communication Sciences, 2004. 4(2): p. 115-137.

27. Kahn and Strong. Product and Service Performance Model for Information Quality: an update. in 4th International Conference on Information Quality. 1998. Boston, Massachusetts, USA.

28. Xu, H. and A. Koronios, Understanding Information Quality in E-business. Journal of Computer Information Sytems, 2004. 45(2): p. 73-82.

29. Rittberger, M. Certification of Information Services. in Proceedings of the 1999 Conference on Information Quality. 1999. Boston, Massachusetts, USA.

30. English, L., Improving Data Warehouse and Business Information Quality. 1999, New York: Wiley \& Sons.

31. Li, S. and B. Lin, Accessing Information Sharing and Information Quality in Supply Chain Management. Decision Support Systems, 2006. 42(3): p. 1641-1656.

32. Ballou, D.P. and G.K. Tayi, Enhancing Data Quality in Data Warehouse Environments. Communications of the ACM, 1999. 42(1): p. 73-78.

33. Fisher, C., et al., Introduction to Information Quality. 2006: MIT.

34. Goodhue, D.L., Understanding user evaluations of Information Systems. Management Science, 1995. 41(12): p. 1827-1842.

35. Misser, P., et al., Improving data quality in practice: a case study in the Italian public 
administration. Distributed and Parallel Databases, 2003. 13(2): p. 125-169.

36. Ballou, D.P. and H. Pazher, Modeling completeness versus consistency tradeoffs in information decision contexts. IEEE Transactions in Knowledge and Data Engineering, 2003. 15(1): p. 240-243.

37. Wang, R.Y., A Product Perspective on Total Quality Management. Communications of the ACM, 1998. 41(2): p. 58-65.

38. Brinkkemper, S., K. Lyytinen, and R.J. Welke, Method Engineering Principles of method construction and tool support. 1996: Chapman \& Hall.

39. Punter, T. and K. Lemmen, The META-model: towards a new approach for Method Engineering. Information and Software Technology, 1996. 38(4): p. 295-305.

40. Gutzwiller, T., Das CC fur den Entwurf von betrieblichen, transaktionsrieentierten Informationssytems, Physica. 1994: Heidelberg.

41. Greenwald, R., R. Stackowiak, and R. Stern, Oracle Essentials: Oracle Database 11g. 4th ed. 2004: O Reilly.

42. Field, A. and G. Hole, How to Design and Report Experiments. 2006.

43. Caulcutt, R., Statistics in research and development. 1991: CRC Press. 